\title{
OLHARES SOBRE A COMPETÊNCIA DO PROFESSOR DE LÍNGUA ESTRANGEIRA: DA FORMAÇÃO AO DESEMPENHO PROFISSIONAL
}

\author{
Douglas Altamiro Consolo; Vera Lúcia Teixeira da Silva (Orgs.) \\ Resenha por JULIANA REICHERT ASSUNÇÃO TONELLI (CAPES/PG-UEL)
}

A obra "Olhares sobre a competência do professor de língua estrangeira: da formação ao desempenho profissional" compila, em sua essência, estudos realizados pelos membros do grupo de pesquisa ENAPLE-CCC (Ensino e Aprendizagem de Língua Estrangeira: crenças, construtos e competências, UNESP/ CNPq), vinculado à UNESP (Universidade Estadual Paulista "Júlio de Mesquita Filho").

Os trabalhos apresentados exploram fundamentalmente questões relacionadas à formação de professores de línguas e discutem aspectos concernentes à competência de professores de línguas estrangeiras, com foco tanto na formação quanto na atuação profissional.

A obra está dividida em treze capítulos. No capítulo introdutório, os organizadores assumem o uso do termo competência como capacidade, embasamento teórico e "aura de poder" (p. 13), para que ações com finalidades pedagógicas sejam realizadas. Enfatizam que a capacidade profissional está apoiada na personalidade do professor, que é única e individual, mas que pode ser refinada se estiver ancorada em conhecimentos teóricos, práticos e em reflexões sobre a sua própria prática pedagógica.

No primeiro capítulo, Maria Lúcia Camargo aborda a questão do conflito entre os conhecimentos teóricos os quais o aluno-professor é exposto durante o processo de formação inicial e os conhecimentos ou práticas que circulam em situações reais encontradas em sala de aula. A autora sugere uma nova estruturação nos cursos de formação de Letras que considere tanto os princípios teóricos quanto as experiências de sala de aula, a fim de que o professor em formação busque refletir sobre sua própria prática e adquira mais autonomia profissional.

Marcelo Concário discute, no segundo capítulo, a consciência linguística como um dos fatores necessários à formação de professores de línguas e questiona se um programa de formação de professores, calcado em discussões e reflexões sobre tal consciência, pode promover uma nova prática de ensino. A pesquisa desenvolvida por Concário mostra que estudos acerca da consciência linguística afetam diretamente o desenvolvimento da competência do professor de línguas, promovendo ganhos tais como: a sensibilização desse 
profissional nas suas experiências linguisticas, proporcionando-o momentos de reflexão para o aprimoramento da sua própria competência comunicativa; reavaliação crítica de suas crenças acerca da prática de ensino, em especial nas situações de apresentação de conteúdos e; tratamento de erros e momentos de interação entre professor e aluno.

No terceiro capítulo, Cláudia Hilsdorf Rocha e Kleber Aparecido da Silva tratam das competências do professor de ensino de línguas sob o escopo da teoria de gêneros, acreditando que tal pressuposto teórico possa dar suporte a um curso de formação de professores que desenvolva as competências necessárias para a atuação de tais profissionais.

Assumindo a concepção bakhtiniana de linguagem/língua, Rocha e Silva entendem que essa se realiza por meio de gêneros discursivos. Privilegiando, portanto, uma visão enunciativa da linguagem e uma proposta sociointeracionista de aprendizagem, os autores defendem que o domínio do uso dos gêneros pode permitir o desenvolvimento de competências que auxiliem o desenvolvimento profissional do professor de línguas, em especial, o domínio da língua estrangeira em práticas sociais menos comuns ou mais elaboradas.

Em seguida, Edevaldo de Souza Pinto traz um relato de um estudo realizado com o objetivo de verificar como se configura, na oralidade, a competência gramatical - tomada como um dos componentes da competência comunicativa e propõem tarefas que propiciem o desenvolvimento do processo de aquisição de certos aspectos gramaticais presentes na produção oral.

A proposta do pesquisador é a de uma prática de ensino intencionalmente voltada para a forma, mas que privilegie também a história de aprendizagem dos alunos. Em suma, sugere atividades com enfoque gramatical que possam promover avanços na interlíngua dos alunos de línguas estrangeiras, com enfoque especial no desenvolvimento/aprimoramento da produção oral.

No quinto capítulo, Daniel Fernando Rodrigues busca definir competência lexical em língua estrangeira e defende a necessidade de se repensar o ensino da língua inglesa dentro dos cursos de Letras. Mais especificamente, o desenvolvimento da oralidade e do ensino do léxico, uma vez que, de acordo com o estudo desenvolvido, muitas vezes, os professores em formação não têm a oportunidade de estar em contato com a língua fora do ambiente de ensino. Conclui, portanto, ser papel dos formadores propiciar condições para que o professor em formação atinja a competência lexical necessária para que possa, futuramente, conduzir suas aulas em língua estrangeira. 
Mariela Zebian Bassetti traz um relato, no sexto capítulo, de sua experiência em observação de atividades voltadas para a produção oral em aulas de língua inglesa no Ensino Fundamental. O objetivo do trabalho em questão é o de colaborar para que a professora sujeito da pesquisa conscientize-se da importância de mostrar aos alunos o real objetivo das atividades propostas e da necessidade de refletir sobre sua prática pedagógica, promovendo benefícios reais tanto para os alunos quanto para o professor.

No sétimo capítulo, Marisa Baldani Peres Ibrahim retoma os fundamentos teóricos discutidos nos três primeiros capítulos sobre as competências do professor de línguas estrangeiras (em especial as noções de competência desenvolvidas por Almeida Filho $(1993 / 2002,1999)$ e direciona, de maneira mais aprofundada, as questões relacionadas à proficiência oral. Para isto, Ibrahim traz um estudo no qual compara a competência oral e os estilos discursivos de duas professoras de inglês no Brasil: uma falante nativa e outra nãonativa. A metodologia utilizada constituiu-se na aplicação do Teste de Proficiência Oral em Língua Estrangeira (TEPOLI); um questionário e uma entrevista para conhecer a formação e o perfil profissional das professoras e; um segundo questionário para verificar os estilos de ensinar. Os resultados mostram poucas diferenças quanto à proficiência oral das professoras e evidenciam que possuir competência linguistica não assegura o bom desempenho no ensino de línguas estrangeiras. Ao comparar professores nativos e não-nativos, a questão discursiva e a interação professor/aluno são os aspectos mais representativos. Além disto, a autora aponta para o fato de que os diferentes estilos de personalidade podem exercer influência sobre as falas e sobre os discursos em sala de aula.

No oitavo capítulo, Douglas Altamiro Consolo discute em que medida a proficiência oral pode influenciar o trabalho de professores de línguas. Nesta perspectiva, o autor trata da diversidade nos perfis de egressos dos cursos de Licenciatura em Letras, dos aspectos políticos e educacionais que entremeiam essa profissão e amplia a discussão sobre avaliação de proficiência linguistica.

Ao trazer um panorama das pesquisas desenvolvidas acerca do tema em tela, Consolo conclui que a formação dos futuros professores de língua estrangeira deva desenvolver-se a partir de pesquisas que possam oferecer um suporte mais sólido para que os professoresformadores (re) conheçam a diversidade das necessidades e objetivos dos aluno-professores.

Maria Sueli Ribeiro da Silva discute, no nono capítulo, a necessidade de se distinguir o ensino de língua estrangeira voltado aos objetivos gerais do ensino de línguas com propósitos instrumentais. Para isto, a autora defende a importância da conscientização do professor de 
línguas quanto à variedade de necessidades que levam um aluno a aprender um novo idioma.

Silva descreve sua experiência, no ensino de Italiano, com propósitos específicos e destaca a importância de se partir do conhecimento prévio dos alunos, explorar o reconhecimento do texto a ser estudado e então partir para o conhecimento linguistico. A autora defende a necessidade de se considerar os saberes e as competências necessárias para cada tipo de curso e mostra em que medida as contribuições do campo da Terminologia específica dos assuntos de interesse dos alunos podem colaborar para a conscientização lexical.

No décimo capítulo, Elen Dias discute como a pesquisa-ação pode contribuir na construção da competência para refletir sobre o processo de ensino-aprendizagem. Ao abordar a importância da conscientização do professor em formação no que tange aos processos envolvidos no ensino-aprendizagem e nas interações estabelecidas na sala de aula, discute também como as crenças dos sujeitos envolvidos no processo de ensino-aprendizagem podem influenciar a formação docente, principalmente, na competência oral dos futuros professores.

Com base em um conjunto de dados envolvendo observações de aulas, com anotações e diários reflexivos; gravações audio-visuais de aulas; questionários com perguntas abertas e fechadas; entrevistas e um teste oral (TEPOLI, também utilizado nos estudos de Ibrahim) além de outros procedimentos, a autora (re)visita conceitos como 1) a competência oral do professor de línguas, 2) competência comunicativa, proficiência e influência oral e; 3) as crenças e culturas do aprender, ensinar e avaliar em língua estrangeira. Sem desconsiderar o dizer e o fazer do aluno, Dias conclui que o engajamento dos sujeitos direta ou indiretamente envolvidos no processo de ensino-aprendizagem de uma língua reflete-se em uma formação inicial mais comprometida.

Na sequência, Angélica Karim Garcia Simão apresenta um estudo desenvolvido com aprendizes de espanhol como língua estrangeira, comparando atividades orientadas pelo material didático e atividades orientadas por tarefas. A autora discute ainda fundamentos da pesquisa-ação, buscando incentivar os professores a pesquisarem suas ações enquanto participantes do processo de ensino.

No capítulo doze, Vera Lúcia Teixeira da Silva traz os resultados de uma pesquisa sobre a visão dos alunos e dos professores do curso de Letras sobre a avaliação. Trata também da importância desta questão na formação de professores, a fim de que os mesmos sejam bem instrumentalizados para avaliar seus futuros alunos. Nesta perspectiva, a autora defende a 
necessidade de que o aluno-professor receba uma formação adequada para o processo de avaliação.

A inclusão de diferentes teorias para discutir a questão das competências do professor apresentando resultados de pesquisas na área de formação de professores oferece ao leitor uma visão menos inocente das inúmeras possibilidades de se pensar a formação e o desempenho do professor de línguas estrangeiras.

Os termos "competência" e "capacidade" são, na obra como um todo, tomados como sinônimos ou como algo muito próximo, sendo este um campo de discussão que vem sendo amplamente investigado e discutido, revelando a dificuldade em definir tais conceitos conforme aumenta a necessidade de utilizá-los.

Os estudos apresentados nesta coletânea, cujo título remete-nos às questões dos saberes necessários para a formação e atuação docente, mereceriam, a nosso ver, um capítulo que discutisse como as noções de competência, capacidade, conhecimento, habilidade ou "competência implícita", conforme discutido por Camargo no primeiro capítulo, podem distanciar-se ou se aproximar quando falamos em formação de professores de língua estrangeira.

A partir dessa breve revisão, torna-se possível perceber a relevância da obra "Olhares sobre a competência do professor de língua estrangeira: da formação ao desempenho". Ao abordar, sob uma perspectiva plural, a complexidade de temas envolvidos na formação do professor de línguas estrangeiras, os artigos desse livro permitem uma reflexão mais aprofundada sobre o tema em questão e convidam o leitor a refletir sobre as muitas implicações no ensino, aprendizagem e avaliação de línguas estrangeiras.

Referência completa: CONSOLO, Douglas Altamiro e SILVA, Vera Lúcia Teixeira da. (Orgs). $1^{a}$ ed. São José do Rio Preto, SP: HN, 2007, 298 p. 